\title{
The ivory tower of academia and how mental health is often neglected
}

\author{
Catherine M Rawlins*,1 (iD) \\ ${ }^{1}$ Université de Bordeaux, Chimie \& Biologie des Membranes et des Nano-objects (CBMN) - CNRS UMR 5248, Pessac 33600, France \\ *Author for correspondence: catherine.rawlins@u-bordeaux.fr
}

\section{"Academics are notorious for having competitions on who is suffering the most."}

\section{First draft submitted: 8 March 2019; Accepted for publication: 15 March 2019; Published online:} 3 May 2019

Whether you are in the thick of graduate school or a tenured professor struggling to obtain the next grant, the truth is, academia operates in a culture of extreme competitiveness. I am certainly not the first person to make the 'ivory tower' metaphor when describing the academic environment. Even in the best departments, egos run unchecked and many are not held accountable for their actions on how they treat their students, colleagues and collaborators. Increasing competitiveness for grants and publications, the privatization of universities, a decline in tenured faculty positions, low pay and minimal benefits are just some of the stressors academics face [1]. With all of this, it is no wonder that mental health is a serious issue in academia and it is imperative that we talk honestly about how it is affecting the scientific enterprise.

As someone who has recently obtained their $\mathrm{PhD}$, I can say with certainty that I had a great graduate education at a top school; I was able to attend conferences, published a few papers and had access to excellent training and instrumentation that prepared me well for my current postdoctoral position. However, I cannot deny that for a majority of graduate school I was depressed and struggled with mental health issues along with job related issues (e.g., switching advisors and sexual harassment). Anxiety and depression can affect anyone and graduate students are particularly vulnerable; an article in C\&EN News reported on the suicide of a graduate student and highlighted how easily mental health can decline while pursuing a PhD [2]. In 2018, there was a published study in Nature which found that $40 \%$ of the 2279 students surveyed around the world had anxiety and depression scores in the moderate to severe range [3]. Graduate students are placed in a tenuous position with the duality of being both a student and an employee. You are expected to teach courses and conduct lab work for which the university profits, but when it comes to matters regarding benefits, pay and other job-related support, you are treated like a student. Moreover, there is no regulation of the number of hours students work, vacation time and how you are treated by your superiors. In USA, much to the chagrin of neoliberal universities, there has been an increase of graduate students unionizing to improve their quality of life and to take some control over their working conditions [4].

Many of the mental health challenges faced in graduate school carry over into the behaviors and methods of future academics; thus, the vicious cycle continues. After completing a $\mathrm{PhD}$, moving to a new institution and starting a new position in academia, these problems do not go away. Academics are notorious for having competitions on who is suffering the most. There are countless stories of late hours, working through weekends and not taking vacations, all under the guise that the work being done is more noble than nonacademics. The fallout of this is poor physical and mental health and a deterioration of one's personal life. Friendships, family and social life all fall by the wayside and you lose sight of who you are as a person outside of your position. Academia is built on the exploitation of often well-meaning academics, but the higher you rise, the greater the workload, the greater the pressure and the greater the fall. What is worse, if you try to achieve the sought-after work-life balance, you are seen as not working hard enough and judged by your colleagues. In my efforts to avoid this, I volunteered with my local section of the American Chemical Society since the beginning of my PhD, which gave me a nonlab work related outlet, helping me develop skills and make new friends and contacts. Naturally, I was criticized by my colleagues for not being committed enough to my lab work, but it was the best decision I made and ensured I had marketable skills outside of the ivory tower. 
There are many things that have make success in academia difficult and too many to fit in one article; for instance, I have not addressed the additional challenges that people of color, LGBTQ+ and single parents face. Although this article is from a heterosexual, white and American perspective, it is still my hope that if these experiences resonate with you and you are struggling, that you seek help. It was through the support of friends, family and my therapist that I was able to complete my degree and manage the mental load of graduate school a bit better. I want to close this editorial with my perspective now that I am looking back at graduate school a few months into my new position. I moved from USA to France which has its challenges in addition to making the transition from a graduate student to a postdoc. Already I see an improvement in my productivity now that I am in a healthier work environment where work/life balance is achievable and encouraged. The system is flawed and unjust, but we as individuals can do our part to change the toxic work environment for the next generation. We have to make efforts going forward not to be complicit in the exploitation of our fellow colleagues and the people we mentor. If you are questioning your future career in academia, I highly recommend the book 'The Professor is In' by Dr Karen Kelsky who gives a frank and honest assessment of what a career as an academic is really like [5]. Although the academic system is tough to navigate and positive change in the ivory tower has a long way to go, take charge of what you can control such as your own happiness and mental health.

\section{Financial \& competing interests disclosure}

The authors have no relevant affiliations or financial involvement with any organization or entity with a financial interest in or financial conflict with the subject matter or materials discussed in the manuscript. This includes employment, consultancies, honoraria, stock ownership or options, expert testimony, grants or patents received or pending, or royalties.

No writing assistance was utilized in the production of this manuscript.

\section{Open access}

This work is licensed under the Attribution-NonCommercial-NoDerivatives 4.0 Unported License. To view a copy of this license, visit http://creativecommons.org/licenses/by-nc-nd/4.0/

\section{References}

1. Chhabra A. Mental health in academia is too often a forgotten footnote. That needs to change. Science doi:10.1126/science.caredit.aat9259 (2018) (epub ahead of print/In Press).

2. Kemsley J. Grappling with graduate student mental health and suicide. Chem. Eng. News 95(32), 28-33 (2017).

3. Evans TM, Bira L, Gastelum JB, Weiss LT, Vanderford NL. Evidence for a mental health crisis in graduate education. Nat. Biotech. 36(3), 282 (2018).

4. Benderly BL. The push for graduate student unions signals a deep structural shift in academia. Science doi:10.1126/science.caredit.aau3970 (2018) (epub ahead of print/In Press).

5. Kelsky K. The Professor is in: the Essential Guide to Turning your Ph.D. into a Job. (First edition.). Three Rivers Press, NY, USA. (2015). 